\title{
Forest entomology in Canada: celebrating a century of science excellence
}

\author{
David W. Langor, René I. Alfaro
}

Forests dominate the Canadian landscape, covering over half the area of our country, spanning $23^{\circ}$ of latitude and $88.5^{\circ}$ of longitude, and accounting for about $10 \%$ of the Earth's forested area. The way of life for many of our aboriginal ancestors was, and still is, intimately tied to forests. In what is now Canada, early European settlers carved out colonies from forests in order to survive and made use of the inherent wealth of goods and services of forests. Canada's economic and social ties to forests are still strong, and forests influence much of the Canadian psyche and way of life, and they contribute significantly to our national prosperity.

Given our wealth of forests, and their importance to the Canadian identity, economy, and social fabric, it is not surprising that a strong tradition of forest science arose in Canada to help us understand, use, and protect our diverse forested ecosystems. There has been tremendous national investment in forest science over the last century, and Canada has emerged as a wellrespected and influential global leader in this broad area of science. From the initial realisation, in the early 20th century, of the vast economic potential of Canadian forests, there also arose a consciousness of the threats to forests, especially forest fires and insects, which might undermine economic aspirations. The Destructive Insects and Pests Act of 1910 gave rise to the first concerted national attention to forest entomology, and it was quickly followed by the allocation of resources to construct research facilities, hire personnel, and fund research on forest entomology. Of course, there was earlier attention to insects associated with Canadian forest ecosystems, beginning in the first half of the 19th century, but most of this simply focussed on documenting species and describing damage to trees. Nonetheless, these descriptive activities provided the earliest taxonomic foundation to support the emergence of 'economic forest entomology'.

The field of forest entomology has a long, proud, innovative, and influential history in Canada, yet this area of science has never been comprehensively reviewed and showcased. In late 2011, the concept of developing a major symposium to review and celebrate forest entomology in Canada was first vetted, with a strong positive reception from the Canadian scientific community. Although this event did not materialise, the enthusiastic interest of prospective symposium participants in developing a publication to celebrate forest entomology in Canada resulted in a detailed proposal, in early 2013, that eventually led to the preparation of this current Supplementary issue of The Canadian Entomologist. The project received generous support from Natural Resources Canada Canadian Forest Service and, with the patience and perseverance of all involved, the outcome is this set of 14 review papers that showcase forest entomology in Canada. Each author was asked to focus on reviewing the state of science in Canada, highlight the contributions by Canadian forest entomologists, and draw attention to gaps and emerging opportunities that might help to provide future direction for the science of forest entomology in our country.

René Alfaro and David Langor introduce this set of papers with an overview of the changing paradigms that have influenced the direction of forest entomology over the last century. Since the early descriptive work documenting the forest insect fauna and the damage caused by destructive species, forest entomology has passed through four paradigm shifts, each triggered by new societal

D. Langor, Canadian Forest Service, Natural Resources Canada, 5320-122 St. NW Edmonton, Alberta, T6H 3S5, Canada René I. Alfaro, Canadian Forest Service, Natural Resources Canada, 506 West Burnside Rd, Victoria, British Columbia, V8N 4W7, Canada

Langor, D.W. and Alfaro, R.I. (eds.) Forest Entomology in Canada: Celebrating a Century of Science Excellence doi:10.4039/tce. 2016.35 
demands of forests and forest entomologists: the pest control or forest protection phase, the integrated pest management phase, the forest health phase, and the ecosystem-based management phase. This paper reviews these paradigm shifts and how the science of forest entomology has changed and adapted to meet new societal demands.

To further set the stage for subsequent reviews of specific science topics, Dan Quiring et al. provide a fascinating review of some major trends in Canadian forest entomology. They describe the changing role of the federal government in forest entomology, the general trends in the publication of forest entomology articles in peer-reviewed journals from 1926 to 2012 and the journals selected by Canadian forest entomologists for publication, the transition in forest entomology research activity from the Canadian Forest Service to universities since about 1970, and the role of women in Canadian forest entomology.

There are five papers that review the ecology, population dynamics, and damage caused by specific groups of insect pests. Vince Nealis describes the comparative ecology of four species of conifer-feeding budworms (Choristoneura species); he also synthesises a wealth of information and interprets the population behaviour of budworms as a product of tri-trophic interactions (host-budworm-natural enemies) at different scales. Rob Johns et al. provide an overview of 106 species of insect defoliators that are prone to outbreaks in Canada and use this rich literature to examine periodicity, spatial synchronicity, and ecological drivers of outbreaks. Furthermore, case studies are featured to highlight the impact and importance of population studies for seven important defoliators. Brian Aukema et al. focus on bark beetles, first reviewing the significance of J.M. Swaine's foundational work on this group in Canada, then summarising the state of knowledge of the life history and population dynamics of four species of bark beetles in the genus Dendroctonus, and finally highlighting how global changes have altered the population dynamics of some bark beetles. René Alfaro and Alvaro Fuentealba draw attention to the wealth of Canadian science addressing pests of regenerating conifer forests and review the natural history and damage of many important species. Furthermore, they highlight the value of decision support systems to manage these pests, and propose a framework for risk assessment. David MacLean reviews the impacts of insects on tree mortality, productivity, and stand development, focussing mainly on the spruce budworm and mountain pine beetle. He highlights the challenges of making pest damage predictions, and emphasizes that a full understanding of the effects of insect outbreaks must take into account tree mortality, changes in interspecific competition, regeneration, and succession, all of which is complicated by human-caused effects on tree range shifts and forest composition.

Tod Ramsfield reminds us that there are many symbiotic relationships between insects and fungi, and these associations may be devastating to trees and forests in both urban and natural settings. The symbiotic relationships are reviewed for selected invasive insects and pathogens, and several case studies illustrate some new and potentially damaging evolutionary relationships.

Canadian science has made strong contributions to the management of forest insect pests. Five papers showcase advances in forest pest management in Canada. Maya Evenden and Peter Silk provide a comprehensive review of the extensive Canadian research about insect chemical ecology and the current and potential applications of this research to forest insect pest management. Furthermore, they suggest priority areas for increased research and development of applications. Kees van Frankenhuyzen et al. reveal the rich Canadian science heritage in forest pathology and the use of pathogens in forest pest management. They show how foundational science on pathogen taxonomy, mode of action, and ecological interactions has led to the development of an arsenal of pathogen-based products, including baculoviruses and Bacillus thuringiensis, that have almost completely replaced the use of synthetic insecticides in forestry. Chris MacQuarrie et al. provide a detailed history of biological control in Canada that spans more than a century. The 161 biocontrol agents released in Canadian forests have led to the suppression of nine insect pest species and contributed to the control of six more species. Significant Canadian biocontrol programmes are reviewed, successes and challenges highlighted, and the interplay between biocontrol, basic science and environmental concerns described. Steve Holmes and Chris MacQuarrie review the 
considerable Canadian science heritage in chemical control of forest pests that spans almost a century and includes development of new insecticides, formulations, and technologies. They further describe how this field of science evolved, in response to mounting environmental concerns, to continue to develop effective and more environmentally friendly control products and technologies. Timely and accurate monitoring of the extent and severity of insect damage to forests informs pest management decisions. Ron Hall et al. highlight how remote sensing complements field and aerial surveys of pest damage to develop an integrated, multi-scale and multi-source pest monitoring system. This review stresses the need to understand pest-host interactions and damage characteristics for effective remote sensing. A synthesis of the literature about aerial surveys, remote sensing and their integration generates some important lessons and illustrates the roles that remote sensing could serve in forest pest management. Finally, the authors discuss some new and upcoming technological advances that may further aid forest pest monitoring.

The final paper of this issue reminds us that policy development and decisions about forest insect pest management require an understanding of economic implications. Kurt Niquedet et al. provide a brief review of economic theory related to forest pest management, highlight some Canadian applications of economic analysis to this field, and suggest future directions for this field of research.
After reviewing these outstanding contributions, we cannot help but be amazed by the rich Canadian heritage in forest entomology. We have much to be proud of! We also see that in all areas of forest entomology reviewed herein there continue to be critical knowledge gaps as well as new and emerging challenges that will continue to demand the attentions and ingenuity of Canadian forest entomologists well into the future. We hope that you enjoy reading this set of papers, that you feel pride in our Canadian science heritage, and that you will be inspired to build on this exceptional foundation of Canadian innovation and ingenuity.

This collection of papers would not have been possible without the important contributions of many people. First and foremost, we acknowledge the incredible dedication, patience and perseverance of the full authorship team of 38 dedicated individuals. The former and current Editors-in-Chief of The Canadian Entomologist, Chris Buddle and Kevin Floate, respectively, were both enthusiastically supportive of this project, and we appreciate their encouragement and flexibility. We are also grateful to Andrew Smith for doing a fantastic job of technical editing. We greatly appreciated the advice and assistance of Aled Hills of Cambridge University Press throughout this process. Our Canadian Forest Service colleague, Anthony Hopkin, was a never-wavering source of encouragement and support throughout this long process. Finally, Natural Resources Canada - Canadian Forest Service provided the generous financial support for the editing and publishing of this work. 